Gazi University
Journal of Science
http://dergipark.gov.tr/gujs

\title{
Investigation of Laser Polishing on the Surface of the Parts Produced Using Powder Bed Fusion
}

\author{
Safak NESLI* (i), Oguzhan YILMAZ ${ }^{\text {(i) }}$ \\ Advanced Manufacturing Technologies Research Group (AMTRG), Department of Mechanical Engineering, Faculty of Engineering, Gazi \\ University Celal Bayar Boulevard, 06570, Maltepe, Ankara, Turkey
}

\section{Highlights}

- This paper introduces the laser polishing process for the additive manufactured parts.

- An INCONEL - 625 part produced by selective laser melting for the laser polishing process.

- The laser polishing process reduces the surface roughness significantly.

Article Info

Received: 30 Nov 2020 Accepted: 13 July 2021

\section{Keywords}

Additive manufacturing

Laser polishing

Surface roughness reduction

\begin{abstract}
Additive manufacturing ( $\mathrm{AM}$ ) offers high design flexibilities and challenging approaches to produce highly complicated and intricate parts, which could not be possible to be produced with traditional manufacturing methods. However, one of the significant drawbacks of AM processes is, certainly, poor surface qualities, which are not acceptable for end products. Laser polishing (LP) offers an innovative surface-finishing technique that could be used to reduce the surface roughness. This research presents the fundamentals of the LP process, experiments on the additive manufactured part surfaces and the roughness reduction. An INCONEL 625 part produced by selective laser melting (SLM) was selected as the sample for the LP experiments. The results showed that laser polishing is able to enhance the surface finish and the reduction in surface roughness can become from $\mathrm{Ra}=10.91 \mu \mathrm{m}$ to $\mathrm{Ra}=2.347 \mu \mathrm{m}$.
\end{abstract}

\section{INTRODUCTION}

Additive manufacturing (AM) is an advance manufacturing method that builds the parts in a layering manner by reshaping the source material [1]. AM is not only a prototyping technology but also a production method especially for the complex-shaped parts that cannot be produced with traditional manufacturing methods [2]. Due to these advantages, it has become a preferred method especially in the field of space, aviation and biomedical. However, AM parts cannot be directly used in the industry without postprocessing. The high surface roughness value of the AM parts is one of the reasons for this situation [3].

Laser polishing (LP) is an innovative part-finishing technique that can be used to reduce the surface roughness by melting a thin layer of material on the part surface (Figure 1). In the LP, the laser melts a very thin layer on the rough surface. The molten material flows from the peaks to the valleys by the effects of surface tension and gravity. There is no material removal in LP, but the material is relocated as a melt pool. During the LP process when the laser sends rays to the surface, it can be said that a significant part of its energy will be absorbed into the work-piece, and the rest will be reflected. The laser parameters (such as laser power, scan speed etc.) and the surface properties of the work-piece affect the amount of energy absorbed by the part. [4].

In the literature, there are many studies about the LP on the surfaces of AM parts. Marimuthu et.al. carried out experimental research for continuous-wave fibre laser polishing of selective laser melted (SLM) parts to obtain smoother surface by analyzing the melt pool dynamics and controlling laser parameters. The surface roughness was successfully reduced by $76 \%$ in their study [5]. Lamikiz et.al. introduced an LP 
process for metallic sintered parts. In this work, up to $80 \%$ reduction in the Ra parameter has been successfully resulted [6]. Mai et al. used different process parameters in order to investigate the laser polishing of 304 stainless steel. The surface roughness could successfully be improved by $61.5 \%$ in their work [7]. Bures et.al. demonstrated laser polishing of the surface of nickel-based superalloy Inconel 718 produced by metal additive manufacturing. The improvement of the surface roughness was reported as $72 \%$ [8]. Zhihao et.al have worked on the effect of laser polishing on the surface of Inconel 718 alloys. The results showed that the laser polishing process can successfully reduce the surface roughness to around 0.1 $\mu \mathrm{m}$, which was initially around $7 \mu \mathrm{m}[9]$.

The present work focused on reducing the surface roughness of the additive manufactured samples with laser polishing. The high surface roughness in these samples affects the mechanical properties of the part. Hence, this study was conducted to show the potential of laser polishing. The purpose is to investigate the effect of LP on the surface topography and roughness of the additive manufactured INCONEL -625 part.

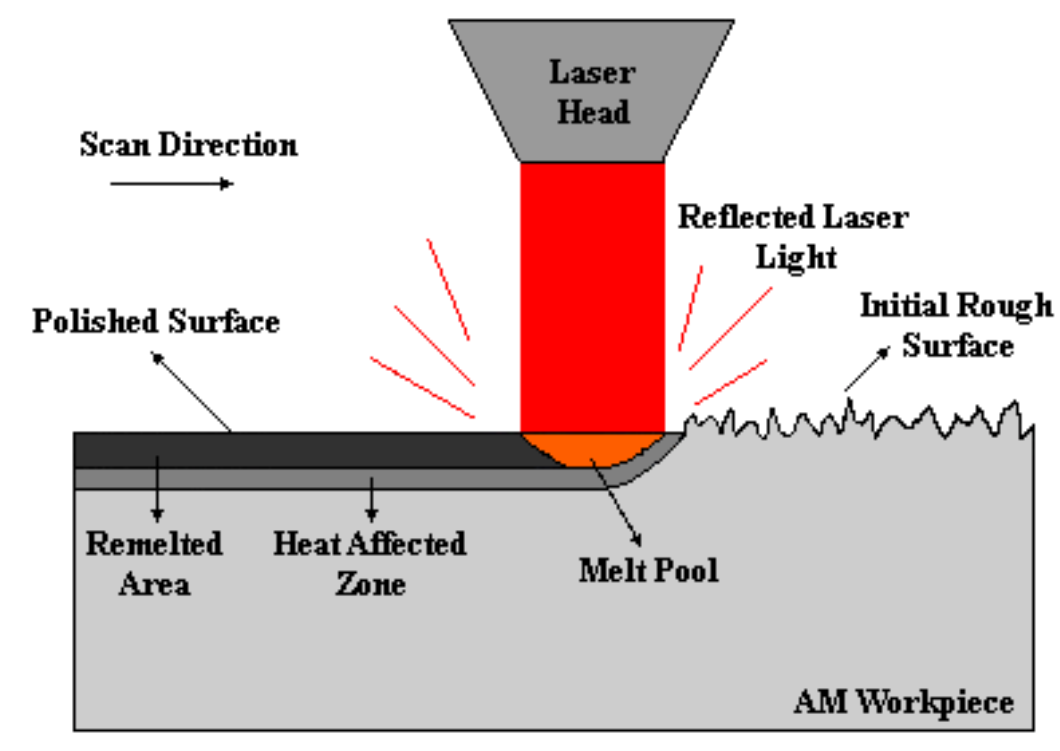

Figure 1. Schematic representation of the LP process [10]

\section{EXPERIMENTAL DETAILS}

In this work, the sample was produced by an EnaVision SLM machine that used 10-40 $\mu$ m Inconel-625 superalloy powder. The production parameters can be seen in Table 1. The dimensions of the rectangular prism-shaped part were 80x11x11 mm (Figure 2).

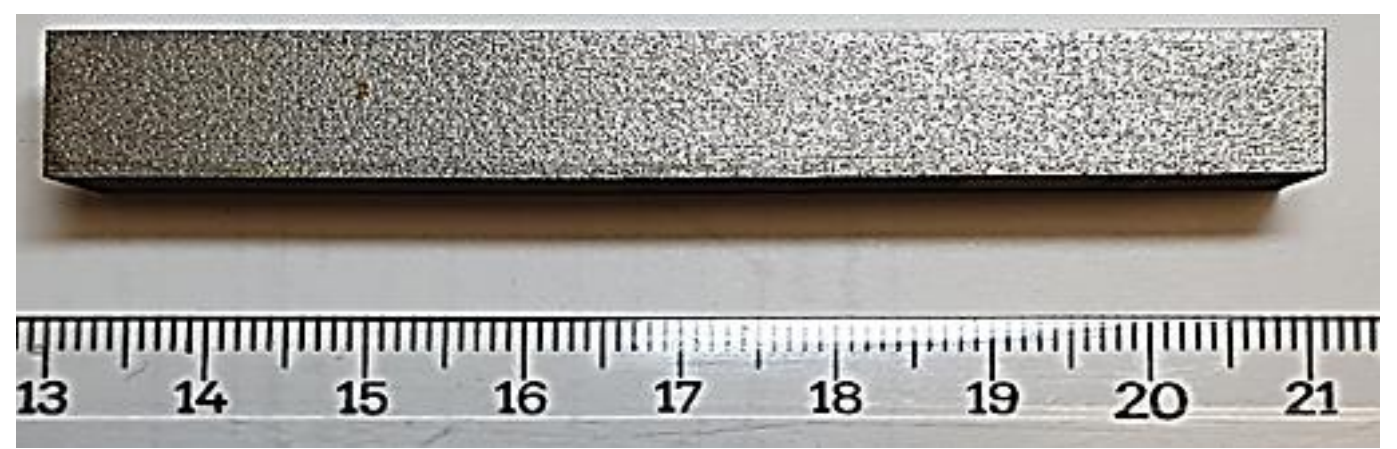

Figure 2. Inconel - 625 part produced by SLM method 
Table 1. SLM process parameters

\begin{tabular}{|c|c|}
\hline SLM Parameters & Value \\
\hline Laser Power & $285 \mathrm{~W}$ \\
\hline Laser Scan Speed & $960 \mathrm{~mm} / \mathrm{s}$ \\
\hline Powder Particle Size & $10-40 \mu \mathrm{m}$ \\
\hline
\end{tabular}

LP was processed on the surface of the SLM-Inconel 625 part, using the laser parameters given in Table 2. The process was covered under argon gas, and the surface roughness of both as-built and polished surfaces were measured and inspected via a white-light interferometer Polytec TopMap Metro.Lab TMS 150 to assess the changes induced by LP.

Table 2. LP process parameters

\begin{tabular}{|c|c|}
\hline LP Parameters & Value \\
\hline Laser Power & $600 \mathrm{~W}$ \\
\hline Laser Scan Speed & $200 \mathrm{~mm} / \mathrm{s}$ \\
\hline Hatch Distance & $0.03 \mathrm{~mm}$ \\
\hline Pulse Frequency & $1000 \mathrm{~Hz}$ \\
\hline Pulse Duration & $0.0008 \mathrm{~s}$ \\
\hline
\end{tabular}

\section{RESULTS AND DISCUSSION}

High roughness values of the AM parts is one of the most crucial problems that needs to be solved. In this work, a new polishing method, LP, was applied onto the surface of AM-Inconel 625 part.

As shown in Figure 3, an area of $8 \times 8 \mathrm{~mm}$ on the AM part surface was laser polished under the protective gas (\%99.999 Argon).

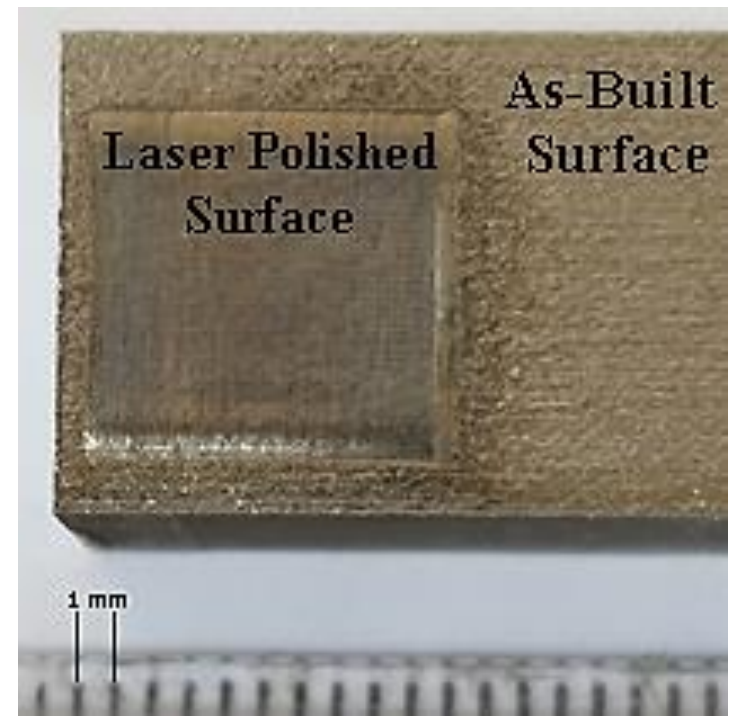

Figure 3. As-built and laser polished surfaces of AM part

Surface roughness values can be numerically defined with the roughness parameters, roughness average $(\mathrm{Ra})$, root-mean-square roughness $(\mathrm{Rq})$, and the average of the height difference between the five highest peaks and the five lowest valleys (Rz) [10]. As can be seen in Figure 3, the surface roughness has decreased significantly. Table 3 indicates that $\mathrm{Ra}, \mathrm{Rq}$ and $\mathrm{Rz}$ values of the as-built area are $10.91 \mu \mathrm{m}, 14.82 \mu \mathrm{m}$ and $64.57 \mu \mathrm{m}$, respectively. Roughness values of the laser polished surface $\mathrm{Ra}, \mathrm{Rq}$ and $\mathrm{Rz}$ are $2.347 \mu \mathrm{m}, 2.840$ $\mu \mathrm{m}$ and $10.76 \mu \mathrm{m}$, respectively. 
Table 3. Roughness values of LP and As-built surfaces

\begin{tabular}{|c|c|c|}
\hline $\begin{array}{c}\text { Roughness } \\
\text { Value }\end{array}$ & $\begin{array}{c}\text { Laser } \\
\text { Polished } \\
\text { Surface }\end{array}$ & $\begin{array}{c}\text { As-built } \\
\text { Surface }\end{array}$ \\
\hline $\mathrm{Ra}$ & $2.347 \mu \mathrm{m}$ & $10.91 \mu \mathrm{m}$ \\
\hline $\mathrm{Rq}$ & $2.840 \mu \mathrm{m}$ & $14.82 \mu \mathrm{m}$ \\
\hline $\mathrm{Rz}$ & $10.76 \mu \mathrm{m}$ & $64.57 \mu \mathrm{m}$ \\
\hline
\end{tabular}

Figure 4 shows the optic microscope view of the surface of the INCONEL - 625 part. With the application of LP onto the surface of the part produced with SLM, it was observed that the surface roughness was successfully improved and Ra values decreased from $10.91 \mu \mathrm{m}$ to $2.347 \mu \mathrm{m}$. In this work, a $78.4 \%$ roughness reduction was successfully achieved in the surface roughness by applying LP.

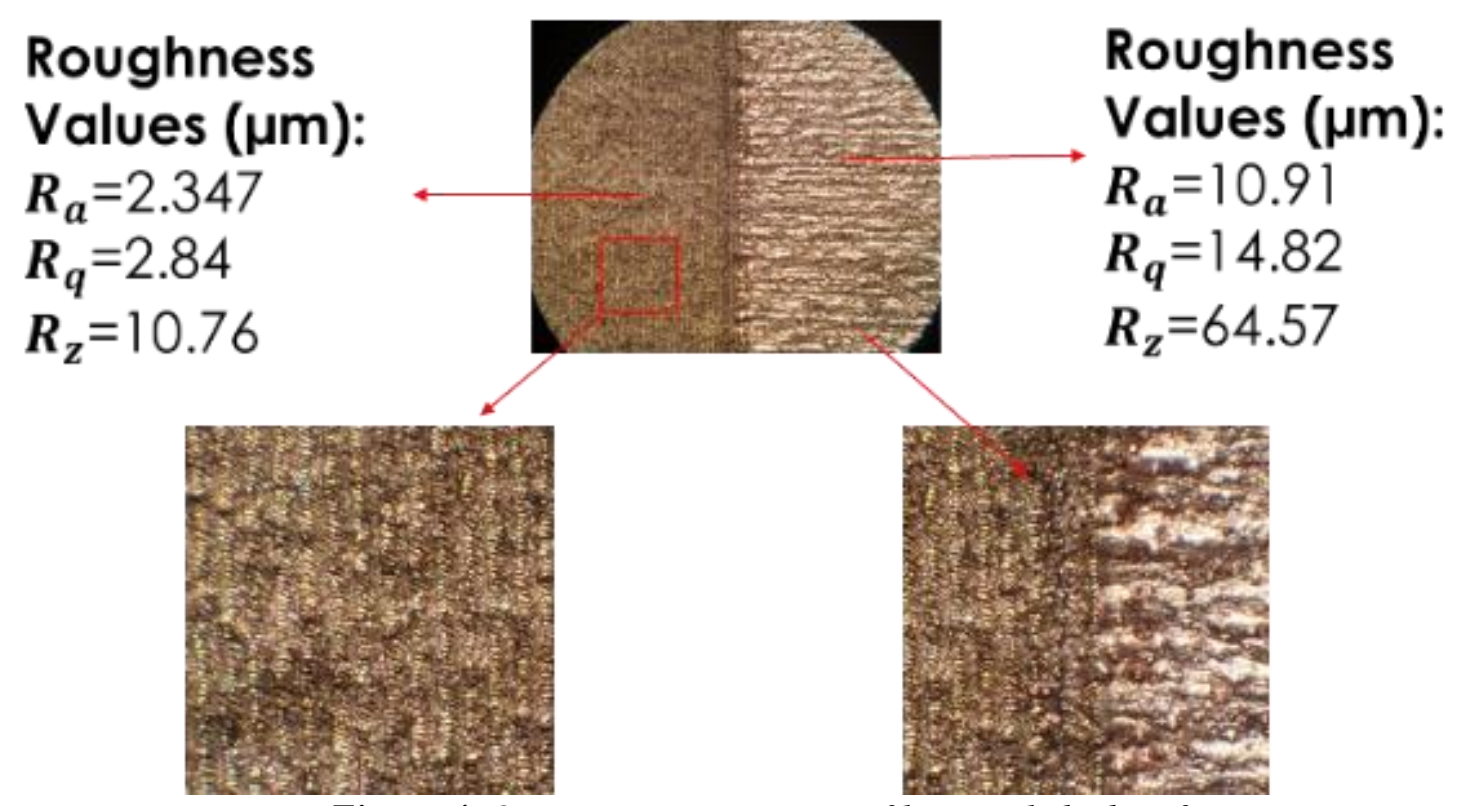

Figure 4. Optic microscope views of laser polished surface

Marimuthu et.al. [5] and Witkin et.al. [11], from two studies on Ti-6Al-4V and Inconel - 625 samples produced with SLM, were able to improve the surface roughness by $76 \%$ and $92 \%$, respectively. Considering the surface roughness levels reached by the studies in the literature, satisfactory results were achieved with the present study. So, it is possible to improve the surface roughness by around $90 \%$ with laser parameter studies.

\section{CONCLUSION}

With the additive manufacturing method, it is foreseen that complex parts will take place more frequently in the industry. The laser polishing, which emerged as an alternative method to traditional methods, can be used to reduce the roughness of the surface, especially complex parts.

In this work, the LP process was applied onto the surface of the Inconel 625 part produced by the SLM method, which is one of the additive manufacturing methods.

As a result of this research, the surface roughness of the AM part could be successfully reduced by $78.4 \%$.

\section{CONFLICTS OF INTEREST}

No conflict of interest was declared by the authors. 


\section{ACKNOWLEDGEMENT}

The paper is presented as an oral presentation in International Conference on Advanced Materials Science and Engineering and High-Tech Device Applications, 02-04 October 2020 in Ankara, Turkey.

\section{REFERENCES}

[1] Gora, W.S., Tian, Y.T., Cabo, A.P., Ardron, M., Maier, R.R.J., Prangnell, P., Weston, N.J., Hand, D.P., "Enhancing surface finish of additively manufactured titanium and cobalt chrome elements using laser based finishing", Physics Procedia, 83: 258-263, (2016).

[2] Qian, M., Xu, W., Brandt, M., Tang, H.P., "Additive manufacturing and postprocessing of Ti-6Al-4V for superior mechanical properties”, MRS Bulletin, 41(10): 775-783, (2016).

[3] Tian, Y., Gora, W.S., Cabo, A.P., Parimi, L.L., Hand, D.P., Tammas-Williams, S., Prangnell, P.B., "Material interactions in laser polishing powder bed additive manufactured Ti6Al4V components", Additive Manufacturing, 20: 11-22, (2017).

[4] Mohajerani, S., Miller, J.D., Tutunea-Fatan, O.R., Bordatchev, E.V., "Thermo-Physical Modelling of Track Width During Laser Polishing of H13 Tool Steel", Procedia Manufacturing, 10: 708-719, (2017).

[5] Marimuthu, S., Triantaphyllou, A., Antar, M., Wimpenny, D., Morton, H., Beard, M., "Laser polishing of selective laser melted components", International Journal of Machine Tools and Manufacture, 95: 97-104, (2015).

[6] Lamikiz, A., Sánchez, J.A., López de Lacalle, L.N., Arana, J.L., "Laser polishing of parts built up by selective laser sintering", International Journal of Machine Tools and Manufacture, 47(12-13): 20402050, (2007).

[7] Mai, T.A., Lim, G.C., "Micromelting and its effects on surface topography and properties in laser polishing of stainless steel”, Journal of Laser Applications, 16(4): 221-228, (2004).

[8] Bures, M., Zetek, M., "Application of Laser Surface Polishing on Additive Manufactured Parts of Inconel 718 Nickel-Based Superalloy”, Mm Science Journal, 2020(1): 3873-3877, (2020).

[9] Zhihao, F., Libin, L., Longfei, C., Yingchun, G., "Laser Polishing of Additive Manufactured Superalloy", 4th CIRP Conference on Surface Integrity, 71: 150-154, (2018).

[10] Nesli, S., Yilmaz, O., "Surface characteristics of laser polished Ti-6Al-4V parts produced by electron beam melting additive manufacturing process", International Journal of Advanced Manufacturing Technology, 114(1): 271-289, (2021).

[11] Witkin, D., Helvajian, H., Steffeney, L., Hansen, W., "Laser Post-Processing of Inconel 625 Made by Selective Laser Melting”, Laser 3D Manufacturing III, 9738, (2016). 